\title{
Impact of Socioeconomic Status on 30-Day and 1-Year Mortalities after Intensive Care Unit Admission in South Korea: A Retrospective Cohort Study
}

\author{
Tak Kyu Oh, Jihoon Jo, Young-Tae Jeon, In-Ae Song \\ Department of Anesthesiology and Pain Medicine, Seoul National University Bundang Hospital, Seongnam, Korea
}

Background: Socioeconomic status (SES) is closely associated with health outcomes, including mortality in critically ill patients admitted to intensive care unit (ICU). However, research regarding this issue is lacking, especially in countries where the National Health Insurance System is mainly responsible for health care. This study aimed to investigate how the SES of ICU patients in South Korea is associated with mortality.

Methods: This was a retrospective observational study of adult patients aged $\geq 20$ years admitted to ICU. Associations between SES-related factors recorded at the time of ICU admission and 30-day and 1-year mortalities were analyzed using univariable and multivariable Cox regression analyses.

Results: A total of 6,008 patients were included. Of these, 394 (6.6\%) died within 30 days of ICU admission, and 1,125 (18.7\%) died within 1 year. Multivariable Cox regression analysis found no significant associations between 30-day mortality after ICU admission and SES factors $(P>0.05)$. However, occupation was significantly associated with 1 -year mortality after ICU admission.

Conclusions: Our study shows that 30-day mortality after ICU admission is not associated with SES in the National Health Insurance coverage setting. However, occupation was associated with 1-year mortality after ICU admission.

Key Words: critical care; intensive care unit; marital status; mortality; occupations; socioeconomic status

\section{INTRODUCTION}

Socioeconomic status (SES) is a total measure of an individual's social and economic statuses and includes income level, education level, and occupation [1]. SES is known to be related to patients' health conditions [2]. Inequality in SES can cause differences in mortality rates [3], making it an important public health issue worldwide [3-5].

In critically ill patients, admission to the intensive care unit (ICU) plays an important role in determining hospital mortality [6]. One of the most important factors associated with the mortality of patients admitted to ICU is a low SES score [7,8]. In addition, insurance coverage in each society and country has been recognized as an important SES factor leading to differences in outcomes. A study conducted in the United States reported that there was a difference in mortality among ICU patients depending on insurance status and coverage types [9].

\section{Original Article}

Received: July 18, 2018

Revised: October 3, 2018

Accepted: October 5, 2018

Corresponding author

In-Ae Song

Department of Anesthesiology and Pain Medicine, Seoul National University Bundang Hospital, 82 Gumi-ro 173beon-gil, Bundang-gu, Seongnam 13620, Korea

Tel: +82-31-787-7499

Fax: +82-31-787-4063

E-mail: songoficu@outlook.kr

Copyright (@) 2018 The Korean Society of Critical Care Medicine

This is an Open Access article distributed under the terms of Creative Attributions Non-Commercial License (http:// creativecommons.org/li-censes/by-nc/4.0/) which permits unrestricted noncommercial use, distribution, and reproduction in any medium, provided the original work is properly cited. 
However, although it is highly possible that the differences in treatment outcomes according to SES or insurance status in patients in ICUs are due to the differences in the health care systems between countries and societies, most cohort studies have been based in the United States [9-11].

In South Korea, patients, including those who are critically ill, can benefit from National Health Insurance when undergoing treatment or surgery [12]. South Korea is also associated with an intense fervor for education [13]. Recently, it was reported that in South Korea, patients' SES before surgery is associated with 30-day and 1-year mortalities after surgery, with marital status correlating with increased mortality [14]. However, there are no studies reporting the association between SES at the time of ICU admission and mortality rate after ICU admission conducted in Asia, including South Korea. Therefore, we conducted this study with the aim of investigating the association between patients' SES and their 30-day and 1-year mortalities after ICU admission in South Korea, where National Health Insurance is compulsory.

\section{MATERIALS AND METHODS}

The present retrospective observational study was approved by the Institutional Review Board of Seoul National University Bundang Hospital (IRB No. B-1804/462-104, approval date: April 13, 2018). Considering the retrospective design of this study, the IRB waived the requirement for informed consent. This study analyzed the medical records of patients aged $\geq 20$ years who were admitted to four ICUs (medical ICU, neurologic ICU, emergency ICU, and surgical ICU) between January 1, 2012, and July 31, 2016. Patients with inaccurate or no medical records were excluded. For patients with $\geq 2$ ICU admissions, only the last admission was included in the analysis.

\section{ICU Staffing from 2012 to 2016}

During the research period, high-intensity day-time (8:00 AM6:00 PM) staffing was executed in each ICU by day-time intensivists (anesthesiologists, pulmonologists, neuro-intensivists, thoracic surgeons), who were responsible for providing patient care in ICUs. On weekends, or during weekday night times, intensivists were on-call; they took calls related to patient severity and procedures. Second- and third-year residents provided the main patient care in ICUs.

\section{Measurements and Outcomes}

The following data were collected from medical records for this research: (1) demographic data (sex/body mass index

\section{KEY MESSAGES}

- Socioeconomic status at the time of intensive care unit (ICU) admission is not independently associated with 30-day mortality after ICU admission, whereas occupation at the time of ICU admission is associated with 1-year mortality.

[BMI, $\left.\mathrm{kg} / \mathrm{m}^{2}\right] /$ age [year]); (2) alcohol use (non-alcohol user/ current alcohol user/former alcohol user) and smoking status (never smoker/current smoker/former smoker); (3) clinical characteristics (Acute Physiology and Chronic Health Evaluation [APACHE] II score, Charlson comorbidity index score, postoperative ICU admission, diagnosis of cancer, length of hospital and ICU stay [day], year of ICU admission, death dates); (4) SES factors (educational level [less than high school/ more than or equal to high school/less than college/more than or equal to college], occupation at ICU admission [office worker/professional job/housework/self-employed/student/ military/day labor/unemployed], marital status [never mar$\mathrm{ried} / \mathrm{married}$, live together/divorced, separated/widowed], religion [Protestant/Catholic/Buddhism/others, e.g., Hinduism, Islam, Chondogyo]), and if the patient belonged to the medical protection group according to the insurance system.

A patient was defined as unemployed when there was no record of a specific job just before entering the ICU. Current smoker or alcohol users were those with a history of smoking or alcohol consumption within 1 month from ICU admission. Medical protection patients are the medically vulnerable officially registered with the National Health Insurance System in South Korea. SES-related information was based on initial nursing information records that were completed either by the patient or their legal guardians at the time of ICU admission. Patients were allowed to refuse disclosure of information regarding their SES. Data regarding the date of death, including those patients who were unavailable for follow-up, were accurately collected after receiving an approval from the Ministry of the Interior and Safety of South Korea. All other data were collected by medical record technicians from medical informatics teams who were blinded to the purpose of the study. The primary aim of this study was to investigate if there are differences in 30-day and 1-year mortalities after ICU admission according to the SES of patients at the time of ICU admission.

\section{Statistical Method}

All patients' baseline characteristics were expressed as num- 
bers with percent or mean with standard deviation. A univariable Cox regression analysis was performed to analyze the simple relationship between 30-day mortality after ICU admission, and each variable. From the univariable Cox regression model, covariates (not SES-related factors) with $\mathrm{P}<0.1$, and all reselected main independent SES-related variables were included in the final multivariable Cox regression analysis. Univariable and multivariable Cox regression analyses were also used for 1-year mortality after ICU admission. In addition, a Kaplan-Meier curve of overall survival time according to occupation post ICU admission was generated after adjustment of covariates with the criterion of $\mathrm{P}<0.05$ in multivariable Cox regression analysis for 1-year mortality. All analyses were performed using IBM SPSS version 24.0 software (IBM Corp., Armonk, NY, USA).

\section{RESULTS}

A total of 8,436 cases of ICU admission among adults aged $\geq 20$ years were recorded between January 2012 and July 2016 . Of these, 169 cases were excluded due to missing or inaccurate SES-related information. Of the remaining 8,267 cases, 2,259 cases who were admitted to an ICU twice or more were also excluded. A total of 6,008 patients were included in the final analysis. Of these, 394 patients (6.6\%) died within 30 days of ICU admission, and 1,125 patients (18.7\%) died within 1 year of ICU admission (Figure 1). Table 1 shows the baseline characteristics of these patients.

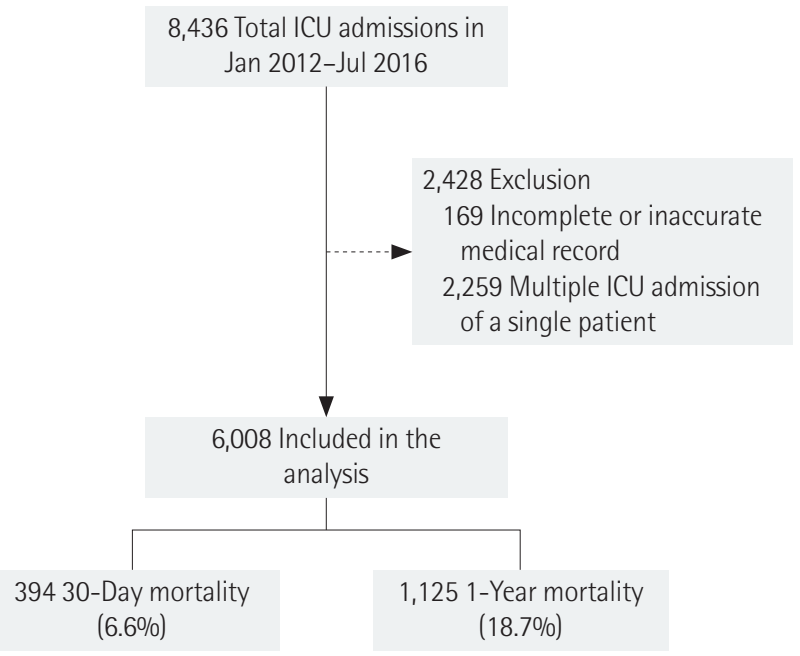

Figure 1. Flowchart for patient selection. ICU: intensive care unit.

\section{0-Day and 1-Year Mortalities after ICU Admissions According to SES}

Supplementary Tables 1 and 2 show the results of univariable Cox regression analysis for 30-day and 1-year mortalities, respectively. Tables 2 and 3 show the results of multivariable Cox regression analyses on 30-day mortality and 1-year mortality after ICU admission, respectively. In the multivariable Cox regression analysis, none of the SES-related factors were significantly associated with 30 -day mortality $(\mathrm{P}>0.05)$. However, occupation at the time of ICU admission was significantly associated with 1-year mortality after ICU admission in the multivariable Cox regression analysis. Of the different occupations, housework was significantly associated with a 53\% increase in 1-year mortality after ICU admission compared with office work (hazard ratio [HR], 1.53; 95\% confidence interval $[\mathrm{CI}], 1.10$ to $2.12 ; \mathrm{P}=0.012$ ). The self-employed group was significantly associated with a $42 \%$ increase (HR, 1.42; 95\% CI, 1.01 to $1.99 ; \mathrm{P}=0.042$ ), student and military or day labor groups were associated with a $45 \%$ increase (HR, 1.45; 95\% $\mathrm{CI}, 1.06$ to 2.00; $\mathrm{P}=0.021$ ), and the unemployed group was associated with an $83 \%$ increase (HR, 1.83; 95\% CI, 1.37 to 2.43; $\mathrm{P}<0.001)$ in 1-year mortality following ICU admission. Figure 2 shows Kaplan-Meier curve of overall survival after ICU admission with adjustment for covariates in the multivariable Cox regression model for 1-year mortality $(\mathrm{P}<0.05)$ and shows

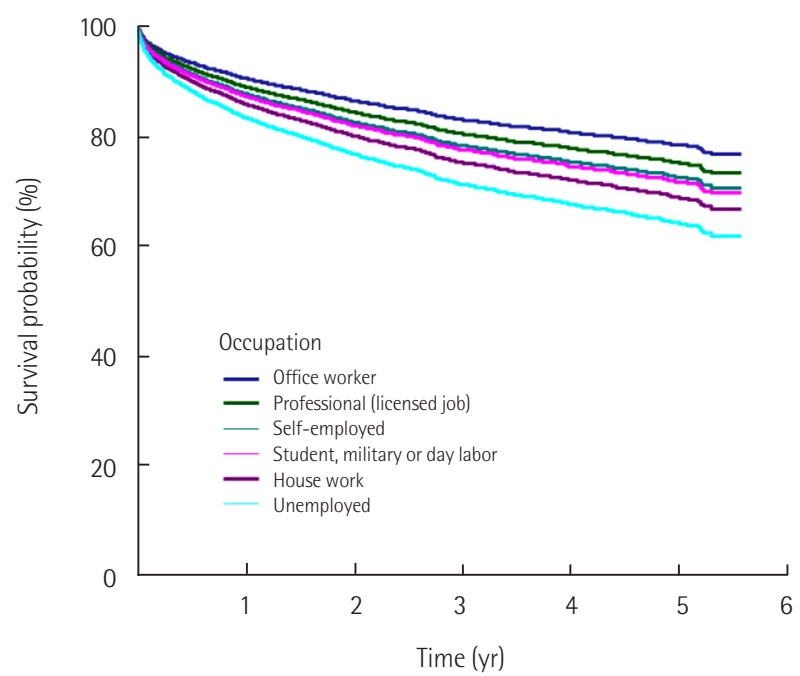

Figure 2. Kaplan-Meier curve of overall survival time according to occupation after adjustment of covariates with criterion of $\mathrm{P}<0.05$ in multivariable Cox regression analysis for 1-year mortality. Included covariates are sex, age, body mass index, Charlson comorbidity index, Acute Physiology and Chronic Health Evaluation II, diagnosis of cancer, postoperative intensive care unit (ICU) admission and year of ICU admission. 
Table 1. Baseline characteristics of total patients admitted to ICU from 2012 to 2016

\begin{tabular}{|c|c|}
\hline Variable & Total $(n=6,008)$ \\
\hline Male sex & $3,662(61.0)$ \\
\hline Age (yr) & $63.7 \pm 15.5$ \\
\hline Body mass index $\left(\mathrm{kg} / \mathrm{m}^{2}\right)$ & $24.2 \pm 3.9$ \\
\hline \multicolumn{2}{|l|}{ Alcohol use } \\
\hline Non-alcohol user & $3,729(62.1)$ \\
\hline Current alcohol user ${ }^{\mathrm{a}}$ & $1,547(25.7)$ \\
\hline Former alcohol user & 732 (12.2) \\
\hline \multicolumn{2}{|l|}{ Smoking status } \\
\hline Never smoker & $3,269(54.4)$ \\
\hline Current smoker $^{\mathrm{a}}$ & 710 (11.8) \\
\hline Former smoker & $2,029(33.8)$ \\
\hline Charlson comorbidity index & $2.3 \pm 2.7$ \\
\hline APACHE II & $20.8 \pm 8.0$ \\
\hline Postoperative ICU admission & $4,746(79)$ \\
\hline Diagnosis of cancer & $1,317(21.9)$ \\
\hline Length of hospital stay (day) & $26.4 \pm 42.2$ \\
\hline Length of ICU stay (day) & $4.3 \pm 8.4$ \\
\hline \multicolumn{2}{|l|}{ Year of ICU admission } \\
\hline 2012 & $1,306(21.7)$ \\
\hline 2013 & $1,225(20.4)$ \\
\hline 2014 & $1,049(17.5)$ \\
\hline 2015 & $1,498(24.9)$ \\
\hline 2016 & 930 (15.5) \\
\hline \multicolumn{2}{|l|}{ Final education level } \\
\hline Less than high school & $2,324(38.7)$ \\
\hline More than or equal to high school, less than college & $1,754(29.2)$ \\
\hline More than or equal to college & $1,930(32.1)$ \\
\hline \multicolumn{2}{|l|}{ Occupation } \\
\hline Office worker & $653(10.9)$ \\
\hline Professional (licensed job) & $290(4.8)$ \\
\hline House work & $1,376(22.9)$ \\
\hline Self-employed & $658(11.0)$ \\
\hline Student, military, or day labor & 765 (12.7) \\
\hline Unemployed & $2,266(37.7)$ \\
\hline \multicolumn{2}{|l|}{ Religion } \\
\hline None & $2,529(42.1)$ \\
\hline Protestant & $1,492(24.8)$ \\
\hline Catholic & 649 (10.8) \\
\hline Buddhism & $1,218(20.3)$ \\
\hline Others (Islam, Hindu, Chondogyo) & $120(2.0)$ \\
\hline \multicolumn{2}{|l|}{ Marital status } \\
\hline Never married & $417(6.9)$ \\
\hline Married or liver together & $4,788(79.5)$ \\
\hline Divorced or separated & $190(3.2)$ \\
\hline Widowed & $623(10.4)$ \\
\hline Medical protection patients ${ }^{\mathrm{b}}$ & $207(3.4)$ \\
\hline 30-Day all-cause mortality after ICU admission & $394(6.6)$ \\
\hline 1-Year all-cause mortality after ICU admission & $1,125(18.7)$ \\
\hline
\end{tabular}

Values are presented as number (\%) or mean \pm standard deviation.

ICU: intensive care unit; APACHE: Acute Physiology and Chronic Health Evaluation.

${ }^{a}$ Current smoker or alcohol users were defined as history of smoking or alcohol consumption within 1 month from ICU admission; ${ }^{b}$ Medical protection patients are population of medically vulnerable group, which are officially registered in National Health Insurance System in South Korea. 
Table 2. Multivariable Cox regression analysis for 30-day mortality after ICU admission in 2012-2016

\begin{tabular}{|c|c|c|}
\hline \multirow{2}{*}{ Variable } & Multivariable model & \multirow{2}{*}{ P-value } \\
\hline & Hazard ratio $(95 \% \mathrm{Cl})$ & \\
\hline Male sex & $1.26(0.94-1.70)$ & 0.127 \\
\hline Age (yr) & $1.00(0.99-1.01)$ & 0.836 \\
\hline Body mass index (kg/m²) & $0.95(0.92-0.97)$ & $<0.001$ \\
\hline Charlson comorbidity index & $1.30(1.26-1.35)$ & $<0.001$ \\
\hline APACHE II & $1.08(1.07-1.10)$ & $<0.001$ \\
\hline Diagnosis of cancer & $1.44(1.15-1.82)$ & 0.002 \\
\hline Postoperative ICU admission & $1.30(1.03-1.64)$ & 0.030 \\
\hline \multicolumn{3}{|l|}{ Socioeconomic status at ICU admission } \\
\hline \multicolumn{3}{|l|}{ Final educational level } \\
\hline Less than high school & 1 & $(0.181)$ \\
\hline More than or equal to high school, less than college & $0.79(0.61-1.02)$ & 0.066 \\
\hline More than or equal to college & $0.88(0.68-1.14)$ & 0.339 \\
\hline \multicolumn{3}{|l|}{ Occupation } \\
\hline Office worker & 1 & $(0.100)$ \\
\hline Professional (licensed job) & $0.60(0.28-1.30)$ & 0.198 \\
\hline House work & $1.56(0.93-2.63)$ & 0.094 \\
\hline Self-employed & $1.17(0.69-1.99)$ & 0.552 \\
\hline Student, military, or day labor & $1.09(0.65-1.82)$ & 0.751 \\
\hline Unemployed & $1.40(0.89-2.18)$ & 0.142 \\
\hline \multicolumn{3}{|l|}{ Religion } \\
\hline None & 1 & $(0.323)$ \\
\hline Protestant & $0.90(0.69-1.18)$ & 0.458 \\
\hline Catholic & $1.28(0.92-1.78)$ & 0.148 \\
\hline Buddhism & $1.11(0.85-1.46)$ & 0.453 \\
\hline Others (Islam, Hindu, Chondogyo) & $1.29(0.68-2.45)$ & 0.439 \\
\hline Medical protection patients ${ }^{\mathrm{a}}$ & $1.04(0.65-1.67)$ & 0.859 \\
\hline
\end{tabular}

All covariates of $\mathrm{P}<0.1$ in univariable Cox regression model were included in the final multivariable Cox regression model with main independent variables (socioeconomic status related factors).

ICU: intensive care unit; $\mathrm{Cl}$ : confidence interval; APACHE: Acute Physiology and Chronic Health Evaluation.

a Medical protection patients are population of medically vulnerable group, which are officially registered in National Health Insurance System in South Korea.

similar tendency to multivariable Cox regression analysis for 1 -year mortality.

\section{DISCUSSION}

This study demonstrates that SES at the time of ICU admission is not independently associated with 30 -day mortality after ICU admission, whereas occupation at the time of ICU admission is associated with 1-year mortality. These results are meaningful as they were adjusted for various demographic and clinical factors including sex, age, BMI, cancer, Charlson comorbidity index, APACHE II, and year of ICU admission.
This study being conducted in an ICU setting, it is notable in that its findings differ from those of previous research in which we reported that marital status, not occupation, is usually associated with 30-day and 1-year mortalities [14].

The main finding of the present study that occupation at ICU admission was associated with 1-year mortality, not 30day mortality, may be explained by certain factors. Firstly, 1-year mortality may reflect long-term mortality for ICU survivors, while 30-day mortality may reflect hospital mortality. Secondly, in critically ill patients, lower SES is known as an associated factor affecting relative long-term mortality rather than short-term mortality [15]. In addition, a study from South 
Table 3. Multivariable Cox regression analysis for 1-year mortality after ICU admission in 2012-2016

\begin{tabular}{|c|c|c|}
\hline \multirow{2}{*}{ Variable } & Multivariable model & \multirow{2}{*}{ P-value } \\
\hline & Hazard ratio $(95 \% \mathrm{Cl})$ & \\
\hline Male sex & $1.24(1.03-1.50)$ & 0.026 \\
\hline Age (yr) & $1.01(1.01-1.02)$ & $<0.001$ \\
\hline Body mass index $\left(\mathrm{kg} / \mathrm{m}^{2}\right)$ & $0.91(0.90-0.92)$ & $<0.001$ \\
\hline \multicolumn{3}{|l|}{ Alcohol consumption } \\
\hline Non-alcohol user & 1 & $(0.789)$ \\
\hline Current alcohol user $^{\mathrm{a}}$ & $0.95(0.81-1.11)$ & 0.493 \\
\hline Former alcohol user & $0.97(0.80-1.18)$ & 0.783 \\
\hline \multicolumn{3}{|l|}{ Smoking status } \\
\hline Never smoker & 1 & $(0.362)$ \\
\hline Current smoker $^{\mathrm{a}}$ & $0.98(0.78-1.23)$ & 0.876 \\
\hline Former smoker & $0.90(0.77-1.05)$ & 0.173 \\
\hline Charlson comorbidity index & $1.20(1.18-1.23)$ & $<0.001$ \\
\hline APACHE II & $1.06(1.05-1.07)$ & $<0.001$ \\
\hline Diagnosis of cancer & $1.78(1.56-2.03)$ & $<0.001$ \\
\hline Postoperative ICU admission & $1.03(0.89-1.18)$ & 0.716 \\
\hline \multicolumn{3}{|l|}{ Year of ICU admission } \\
\hline 2012 & 1 & $(<0.001)$ \\
\hline 2013 & $1.14(0.95-1.37)$ & 0.170 \\
\hline 2014 & $0.87(0.71-1.05)$ & 0.151 \\
\hline 2015 & $0.69(0.57-0.83)$ & $<0.001$ \\
\hline 2016 & $0.63(0.51-0.78)$ & $<0.001$ \\
\hline \multicolumn{3}{|l|}{ Socioeconomic status at ICU admission } \\
\hline \multicolumn{3}{|l|}{ Final educational level } \\
\hline Less than high school & 1 & $(0.722)$ \\
\hline More than or equal to high school, less than college & $0.94(0.81-1.10)$ & 0.448 \\
\hline More than or equal to college & $0.96(0.82-1.12)$ & 0.564 \\
\hline \multicolumn{3}{|l|}{ Occupation } \\
\hline Office worker & 1 & $(<0.001)$ \\
\hline Professional (licensed job) & $1.17(0.76-1.79)$ & 0.485 \\
\hline House work & $1.53(1.10-2.12)$ & 0.012 \\
\hline Self-employed & $1.42(1.01-1.99)$ & 0.042 \\
\hline Student, military, or day labor & $1.45(1.06-2.00)$ & 0.021 \\
\hline Unemployed & $1.83(1.37-2.43)$ & $<0.001$ \\
\hline \multicolumn{3}{|l|}{ Religion } \\
\hline None & 1 & $(0.717)$ \\
\hline Protestant & $0.99(0.84-1.15)$ & 0.849 \\
\hline Catholic & $1.13(0.93-1.38)$ & 0.213 \\
\hline Buddhism & $1.04(0.88-1.22)$ & 0.650 \\
\hline Others (Islam, Hindu, Chondogyo) & $0.97(0.62-1.50)$ & 0.873 \\
\hline Medical protection patients ${ }^{\mathrm{b}}$ & $1.23(0.94-1.60)$ & 0.136 \\
\hline
\end{tabular}

All covariates of $\mathrm{P}<0.1$ in univariable Cox regression model were included in the final multivariable Cox regression model with main independent variables (socioeconomic status related factors).

ICU: intensive care unit; $\mathrm{Cl}$ : confidence interval; APACHE: Acute Physiology and Chronic Health Evaluation.

${ }^{a}$ Current smoker or alcohol users were defined as history of smoking or alcohol consumption within 1 month from ICU admission; ${ }^{b}$ Medical protection patients are population of medically vulnerable group, which are officially registered in National Health Insurance System in South Korea. 
Korea has reported that an office worker undergoes more health check-ups compared to a manual worker [16]. Therefore, the difference in HR of 1-year mortality may be affected by the difference in routine health check-up except for those in professional jobs. Furthermore, there is a possibility that patients who are unemployed and who showed the highest HR in 1-year mortality, could not work due to severe chronic illness such as cancers, at the time of ICU admissions. Therefore, careful interpretation is required to understand the results of the present study.

The present study is meaningful in that it is a cohort study conducted in a setting where the entire nation receives similar benefits from the National Health Insurance system of South Korea with a low financial burden [17]. According to a study conducted in the United States, where private health insurance systems play an important role [18], lack of health insurance increased 30-day mortality after ICU admission. Although there is also a report that expansion of Medicaid services for patients with low income and resources improved mortality in the United States [19], critically ill patients who only have public health insurances still have higher mortality rates than those who have additional private health insurances in the United States [9]. In other words, contrary to South Korea, where all patients receive similar treatments in ICUs through the National Health Insurance Services, in the United States, the type of health insurance one holds is the most important SES-related factor that determines mortality in ICU patients. As such, our study greatly differs from these American studies.

There are countries such as Canada and the United Kingdom where similar to South Korea, the National Health Insurance System is responsible for providing the main health care including ICU care [20]. Regarding previous studies on the association between mortality in ICUs and SES in these countries, one study has reported that a higher SES is associated with lower mortality in the case of elective surgical ICU admission in England and Wales [7]. In countries where a national health insurance system is established, other SES factors, aside from health insurance status, may be independently associated with the mortality of ICU patients, and this study shows that occupation is associated with 1-year mortality.

Another interesting finding of this study is that in the National Health Insurance coverage setting, different results were obtained between 30-day and 1-year mortalities after ICU admission. Firstly, 30-day mortality shares similarities with hospital mortality, which reflects on the health care in ICUs [21]. The fact that 30-day mortality after ICU admission was not independently associated with SES suggests that all patients ad- mitted to ICUs received the same treatment under the National Health Insurance scheme regardless of their SES. In addition, the medical protection patient did not show worse 30day or 1-year mortality after ICU admission, which means the National Health Insurance System supports the economically disadvantaged patients effectively.

Secondly, 1-year mortality after ICU admission is a longterm outcome measure for patients who were critically ill, and SES-related factors may have also affected 1-year mortality. For example, in Canada, where the National Health Insurance System plays the main role in health care, similar to South Korea, Canadians of upper middle SES were more likely to be prioritized in their access to the health care system [22]. Therefore, one of the factors explaining our finding suggests that there may be differences in the level of healthcare access according to SES among ICU patients in South Korea as is the case in Canada. Further research from the perspective of public health care is needed in this regard.

Another point to note is that our results in the general surgical population differed from those of a previous cohort study [14], which reported increased 30-day and 1-year mortalities in the never-married group following surgery, with occupation not affecting mortalities. Such a difference may be attributed to the different characteristics of the two patient groups. In this study, most subjects were critically ill patients with relatively old age and high Charlson comorbidity indices.

This study has a number of limitations. First, due to the limitation of the retrospective cohort design, there may have been a selection bias. However, to prevent such bias, we had medical record technicians blinded from the purpose of this study and the main researchers were also blinded from data until all statistical outcomes were obtained. Second, due to the nature of a cohort study based on 5 years of medical records from a single tertiary care hospital, we cannot generalize the findings from ICUs to all Korean hospitals. Finally, although we had accurate information regarding the date of death of all patients, it was hard to find the causes of death. It was therefore not possible to investigate disease-specific mortality. Despite these limitations, this study is meaningful in that it is the first study to analyze the association between SES factors and 30-day and 1-year mortalities in patients in South Korea where the National Health Insurance System plays the main role in health care.

In conclusion, this study shows that 30-day mortality after ICU admission is not associated with patients' SES in the National Health Insurance coverage setting, while 1-year mortality after ICU admission is associated with occupation. 


\section{CONFLICT OF INTEREST}

No potential conflict of interest relevant to this article was reported.

\section{ORCID}

Tak Kyu Oh https://orcid.org/0000-0002-4027-4423

Jihoon Jo https://orcid.org/0000-0002-9606-2438

Young-Tae Jeon https://orcid.org/0000-0002-4157-2609

In-Ae Song https://orcid.org/0000-0002-7814-4253

\section{SUPPLEMENTARY MATERIALS}

The online-only Supplement data are available with this article online: https://doi.org/10.4266/acc.2018.00514

\section{REFERENCES}

1. Baker EH. Socioeconomic status, definition. In: Cockerham WC, Dingwall R, Quah SR, editors. The Wiley Blackwell encyclopedia of health, illness, behavior, and society. Hoboken: John Wiley \& Sons; 2014.

2. Kennedy BP, Kawachi I, Glass R, Prothrow-Stith D. Income distribution, socioeconomic status, and self rated health in the United States: multilevel analysis. BMJ 1998;317:917-21.

3. Mackenbach JP, Kunst AE, Cavelaars AE, Groenhof F, Geurts JJ; The EU Working Group on Socioeconomic Inequalities in Health. Socioeconomic inequalities in morbidity and mortality in Western Europe. Lancet 1997;349:1655-9.

4. Lantz PM, House JS, Lepkowski JM, Williams DR, Mero RP, Chen J. Socioeconomic factors, health behaviors, and mortality: results from a nationally representative prospective study of US adults. JAMA 1998;279:1703-8.

5. Marmot M. Social determinants of health inequalities. Lancet 2005;365:1099-104.

6. Tran DD, Groeneveld AB, van der Meulen J, Nauta JJ, Strack van Schijndel RJ, Thijs LG. Age, chronic disease, sepsis, organ system failure, and mortality in a medical intensive care unit. Crit Care Med 1990;18:474-9.

7. Hutchings A, Raine R, Brady A, Wildman M, Rowan K. Socioeconomic status and outcome from intensive care in England and Wales. Med Care 2004;42:943-51.

8. Kaufman JS, Cooper RS, McGee DL. Socioeconomic status and health in blacks and whites: the problem of residual confounding and the resiliency of race. Epidemiology 1997;8:621-8. 9. Baldwin MR, Sell JL, Heyden N, Javaid A, Berlin DA, Gonzalez
WC, et al. Race, ethnicity, health insurance, and mortality in older survivors of critical illness. Crit Care Med 2017;45:e583-91.

10. Halpern NA, Pastores SM. Critical care medicine in the United States 2000-2005: an analysis of bed numbers, occupancy rates, payer mix, and costs. Crit Care Med 2010;38:65-71.

11. Milbrandt EB, Kersten A, Rahim MT, Dremsizov TT, Clermont G, Cooper LM, et al. Growth of intensive care unit resource use and its estimated cost in Medicare. Crit Care Med 2008; 36:2504-10.

12. Lim B. Korean medicine coverage in the National Health Insurance in Korea: present situation and critical issues. Integr Med Res 2013;2:81-8.

13. Anderson T, Kohler HP. Education fever and the East Asian fertility puzzle: a case study of low fertility in South Korea. Asian Popul Stud 2013;9:196-215.

14. Oh TK, Kim K, Do SH, Hwang JW, Jeon YT. Association between Socioeconomic status and 30-day and one-year all-cause mortality after surgery in South Korea. J Clin Med 2018;7:E52.

15. Ho KM, Dobb GJ, Knuiman M, Finn J, Webb SA. The effect of socioeconomic status on outcomes for seriously ill patients: a linked data cohort study. Med J Aust 2008;189:26-30.

16. Shin HY, Kang HT, Lee JW, Lim HJ. The association between socioeconomic status and adherence to health check-up in Korean adults, based on the 2010-2012 Korean National Health and Nutrition Examination Survey. Korean J Fam Med 2018; 39:114-21

17. Kwon S. Thirty years of national health insurance in South Korea: lessons for achieving universal health care coverage. Health Policy Plan 2009;24:63-71.

18. Lyon SM, Benson NM, Cooke CR, Iwashyna TJ, Ratcliffe SJ, Kahn JM. The effect of insurance status on mortality and procedural use in critically ill patients. Am J Respir Crit Care Med 2011;184:809-15

19. Sommers BD, Baicker K, Epstein AM. Mortality and access to care among adults after state Medicaid expansions. N Engl J Med 2012;367:1025-34.

20. Hacker JS. The historical logic of national health insurance: structure and sequence in the development of British, Canadian, and U.S. medical policy. Stud Am Polit Dev 1998;12:57-130.

21. Tourangeau AE, Doran DM, McGillis Hall L, O'Brien Pallas L, Pringle D, Tu JV, et al. Impact of hospital nursing care on 30day mortality for acute medical patients. J Adv Nurs 2007;57: 32-44.

22. Alter DA, Iron K, Austin PC, Naylor CD; SESAMI Study Group. Socioeconomic status, service patterns, and perceptions of care among survivors of acute myocardial infarction in Canada. JAMA 2004;291:1100-7. 
Supplementary Table 1. Univariable Cox regression analysis for 30-day mortality after ICU admission in 2012-2016

\begin{tabular}{|c|c|c|}
\hline \multirow{2}{*}{ Variable } & Univariable model & \multirow{2}{*}{ P-value } \\
\hline & Hazard ratio (95\% Cl) & \\
\hline Male sex & $1.24(1.01-1.53)$ & 0.043 \\
\hline Age (yr) & $1.02(1.01-1.03)$ & $<0.001$ \\
\hline Body mass index $\left(\mathrm{kg} / \mathrm{m}^{2}\right)$ & $0.90(0.88-0.93)$ & $<0.001$ \\
\hline \multicolumn{3}{|l|}{ Alcohol consumption } \\
\hline Non-alcohol user & 1 & $(0.351)$ \\
\hline Current alcohol user $^{\mathrm{a}}$ & $0.84(0.66-1.07)$ & 0.154 \\
\hline Former alcohol user & $0.99(0.73-1.35)$ & 0.965 \\
\hline \multicolumn{3}{|l|}{ Smoking status } \\
\hline Never smoker & 1 & $(0.647)$ \\
\hline Current smoker $^{\mathrm{a}}$ & $1.14(0.84-1.54)$ & 0.400 \\
\hline Former smoker & $0.98(0.79-1.22)$ & 0.874 \\
\hline Charlson comorbidity index & $1.39(1.35-1.43)$ & $<0.001$ \\
\hline APACHE II & $1.11(1.10-1.12)$ & $<0.001$ \\
\hline Diagnosis of cancer & $1.35(1.08-1.68)$ & 0.009 \\
\hline Postoperative ICU admission & $0.46(0.37-0.56)$ & $<0.001$ \\
\hline \multicolumn{3}{|l|}{ Year of ICU admission } \\
\hline 2012 & 1 & (0.538) \\
\hline 2013 & $1.21(0.89-1.65)$ & 0.226 \\
\hline 2014 & $1.30(0.95-1.79)$ & 0.101 \\
\hline 2015 & $1.14(0.84-1.54)$ & 0.399 \\
\hline 2016 & $1.09(0.77-1.53)$ & 0.632 \\
\hline \multicolumn{3}{|l|}{ Socioeconomic status at ICU admission } \\
\hline \multicolumn{3}{|l|}{ Final educational level } \\
\hline Less than high school & 1 & $(0.201)$ \\
\hline More than or equal to high school, less than college & $0.82(0.65-1.05)$ & 0.118 \\
\hline More than or equal to college & $0.84(0.67-1.07)$ & 0.155 \\
\hline \multicolumn{3}{|l|}{ Occupation } \\
\hline Office worker & 1 & $(<0.001)$ \\
\hline Professional (licensed job) & $0.75(0.35-1.59)$ & 0.454 \\
\hline House work & $1.38(0.89-2.14)$ & 0.149 \\
\hline Self-employed & $1.18(0.71-1.96)$ & 0.534 \\
\hline Student, military, or day labor & $1.18(0.72-1.93)$ & 0.524 \\
\hline Unemployed & $2.31(1.55-3.45)$ & $<0.001$ \\
\hline \multicolumn{3}{|l|}{ Religion } \\
\hline None & 1 & $(0.514)$ \\
\hline Protestant & $0.88(0.68-1.14)$ & 0.329 \\
\hline Catholic & $1.15(0.84-1.58)$ & 0.392 \\
\hline Buddhism & $1.04(0.80-1.36)$ & 0.764 \\
\hline Others (Islam, Hindu, Chondogyo) & $1.31(0.69-2.49)$ & 0.403 \\
\hline Medical protection patients ${ }^{b}$ & $1.44(0.91-2.28)$ & 0.125 \\
\hline
\end{tabular}

All covariates of $\mathrm{P}<0.1$ in univariable Cox regression model were included in the final multivariable Cox regression model with main independent variables (socioeconomic status related factors).

ICU: intensive care unit; $\mathrm{Cl}$ : confidence interval; APACHE: Acute Physiology and Chronic Health Evaluation.

${ }^{a}$ Current smoker or alcohol users were defined as history of smoking or alcohol consumption within 1 month from ICU admission; ${ }^{b}$ Medical protection patients are population of medically vulnerable group, which are officially registered in National Health Insurance System in South Korea. 
Supplementary Table 2. Univariable Cox regression analysis for 1-year mortality after ICU admission in 2012-2016

\begin{tabular}{|c|c|c|}
\hline \multirow{2}{*}{ Variable } & Univariable model & \multirow{2}{*}{ P-value } \\
\hline & Hazard ratio $(95 \% \mathrm{Cl})$ & \\
\hline Male sex & $1.28(1.13-1.45)$ & $<0.001$ \\
\hline Age (yr) & $1.03(1.02-1.04)$ & $<0.001$ \\
\hline Body mass index $\left(\mathrm{kg} / \mathrm{m}^{2}\right)$ & $0.88(0.86-0.89)$ & $<0.001$ \\
\hline \multicolumn{3}{|l|}{ Alcohol consumption } \\
\hline Non-alcohol user & 1 & $(0.002)$ \\
\hline Current alcohol user $^{\mathrm{a}}$ & $0.77(0.66-0.89)$ & $<0.001$ \\
\hline Former alcohol user & $0.98(0.82-1.17)$ & 0.843 \\
\hline \multicolumn{3}{|l|}{ Smoking status } \\
\hline Never smoker & 1 & $(0.038)$ \\
\hline Current smoker ${ }^{\mathrm{a}}$ & $0.81(0.66-1.00)$ & 0.045 \\
\hline Former smoker & $1.07(0.94-1.21)$ & 0.293 \\
\hline Charlson comorbidity index & $1.28(1.26-1.30)$ & $<0.001$ \\
\hline APACHE II & $1.07(1.06-1.08)$ & $<0.001$ \\
\hline Diagnosis of cancer & $1.86(1.64-2.10)$ & $<0.001$ \\
\hline Postoperative ICU admission & $0.49(0.44-0.56)$ & $<0.001$ \\
\hline \multicolumn{3}{|l|}{ Year of ICU admission } \\
\hline 2012 & 1 & $(0.014)$ \\
\hline 2013 & $1.35(1.12-1.62)$ & 0.001 \\
\hline 2014 & $1.32(1.09-1.60)$ & 0.002 \\
\hline 2015 & $1.21(1.01-1.45)$ & 0.037 \\
\hline 2016 & $1.15(0.94-1.41)$ & 0.181 \\
\hline \multicolumn{3}{|l|}{ Socioeconomic status at ICU admission } \\
\hline \multicolumn{3}{|l|}{ Final educational level } \\
\hline Less than high school & 1 & $(<0.001)$ \\
\hline More than or equal to high school, less than college & $0.80(0.70-0.93)$ & 0.003 \\
\hline More than or equal to college & $0.81(0.70-0.93)$ & 0.002 \\
\hline \multicolumn{3}{|l|}{ Occupation } \\
\hline Office worker & 1 & $(<0.001)$ \\
\hline Professional (licensed job) & $1.24(0.81-1.90)$ & 0.316 \\
\hline House work & $1.60(1.20-2.14)$ & 0.001 \\
\hline Self-employed & $1.43(1.03-1.99)$ & 0.035 \\
\hline Student, military, or day labor & $1.78(1.31-2.42)$ & $<0.001$ \\
\hline Unemployed & $3.33(2.55-4.33)$ & $<0.001$ \\
\hline \multicolumn{3}{|l|}{ Religion } \\
\hline None & 1 & $(0.654)$ \\
\hline Protestant & $0.99(0.85-1.15)$ & 0.851 \\
\hline Catholic & $1.15(0.95-1.39)$ & 0.167 \\
\hline Buddhism & $1.04(0.89-1.22)$ & 0.601 \\
\hline Others (Islam, Hindu, Chondogyo) & $0.98(0.63-1.52)$ & 0.922 \\
\hline Medical protection patients ${ }^{b}$ & $1.65(1.27-2.14)$ & $<0.001$ \\
\hline
\end{tabular}

All covariates of $\mathrm{P}<0.1$ in univariable Cox regression model were included in final multivariable Cox regression model with main independent variables (socioeconomic status related factors).

ICU: intensive care unit; $\mathrm{Cl}$ : confidence interval; APACHE II: Acute Physiology and Chronic Health Evaluation.

${ }^{a}$ Current smoker or alcohol users were defined as history of smoking or alcohol consumption within 1 month from ICU admission; ${ }^{b}$ Medical protection patients are population of medically vulnerable group, which are officially registered in National Health Insurance System in South Korea. 